\title{
DE86 006098
}

ENSDF: THE EVALUATED NUCLEAR STRUCTURE DATA FILE

\author{
M. J. Martin \\ Oak Ridge National Laboratory, Oak Ridge, TN 37831 * \\ ABSTRACT
}

\begin{abstract}
The structure, organization, and contents of the Evaluated Nuclear Structure Data File, ENSDF, will be discussed. This file sumarizes the state of experimental nuclear structure data for all nuclei as determined from consicleration of measurements reported world wide. Special emphasis will be given to the data evaluation procedures and consistency checks utilized at the input stage and to the retrieval capabilities of the system at the output stage.
\end{abstract}

\section{INTRODUCTION}

The Nuclear Data Project, NDP, is a data evaluation center within the Physics Division at ORNL. We are a member of the international Nuclear Structure and Decay Data network, NSDD, which consists of 15 centers in 10 countries. Other US centers are located at Brookhaven National Laboratory, Lawrence Berkeley Laboratory, Idaho National Engineering Laboratory, and the University of Pennsylvania. Responsibility for coordination of the network resides with the National Nuclear Data Center at BNL.

The NSDD has responsibility for the evaluation of nuclear structure and decay data for all nuclides. The centers evaluate measurements of quantities such as excitation energies, spins and parities, half-lives, radiation energies and intensities, and static moments. Regular publication of the evaluations takes place in the journal Nuclear Lata Sheets ${ }^{1}$ for $A>45$ and in the journal Nuclear Physics for $A \leq 45$.

Our responsibility within this network is two-fold. First, we are responsible for the evaluation of mass chains with $A>195$ (excluding even $A=238$ to 244 ). Second, the NDP houses the position of Editor-in-Chief of the Nuclear Data Sheets and so has the ultimate responsibility for the quality of the contents of ENSDF and, consequently, the quality of what is published in the Nuclear Data Sheets.

\section{STRUCTURE OF ENSDF}

In 1971, the NDP designed a formal structure for entering data into a computer file. ${ }^{2}$ This structure has since been adopted by the international network.

The ENSDF file consists of "data sets", each of which summarizes the results from all relevant papers on one type of experiment. Each of these data sets is a collection of records for the levels

*Operated by Martin Marietta Energy Systems, Inc., for the US Department of Energy.

Cy

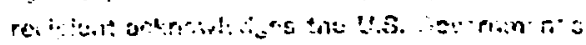
i j:

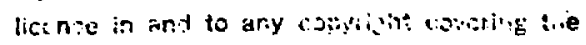
article. 
and radiations observed in the experiment. In addition to the "condensation" involved in the preparation of a data set, the properties of levels and radiations for each nucleus, based on all pertinent data sets, are further summarized in a data set labelled "Adopted Jevels, Gammas". Examples of these data sets can be seen in any issue of the Nuclear Data Sheets.

Documentation for the quantities contained in the file consists of references to the published or informal scientific literature, as well as comments by the evaluator explaining the choice of "best" or "adopted" experimental numbers.

\section{EVALUATION PROCER:RES}

Hork on a given mass chain begins with a reference list containing references for all available articles on nuclei with that mass. This reference list is prepared at BNL by scanning all the pertinent published literature and all the available secondary sources (theses, conference reports, laboratory reports, etc.). The coverage of the published literature is virtually complete.

For each reaction or decay, the evaluator then reads all the papers, evaluates the contents, extracts the pertinen: data, intercompares such data from each source, and finally adopts a value, with an uncertainty, for each quantity to be included in the ENSDF file. To arrive at an adopted value, the evaluator may choose to take a weighted (or unweighted) average of all the experimental numbers or, at the other extreme, to take the result of one paper if the value from that paper is judged to be clearly superior to the others.

In the course of extracting data, the evaluator must check for the possible effect of more recent reliable energy standards, changes in the accepted values of physical "constants," or in reference values. For example, earlier EY data may need to be corrected for the presently accepted 198 Au 411 energy; extraction of a $Q$ value from $\varepsilon_{K} / \varepsilon_{L}$ may have used a value for the fluorescent yield which has subsequently been revised; a $g$ factor inay have been deduced using a half-life for which a better value is presently available. In all cases where changes are made, such changes are carefully documented.

When all data sets yielding information on a given nucleus are completed, the evaluator then prepares the Adopted data sets. Bases for the adopted values are given, and arguments for spin and parity assignments based on established rules are given. In the preparation of all data sets, the evaluator makes use of an extensive set of analysis and checking programs. These range from straightforward calculational programs such as those for internal conversion coefficients, $\log \mathrm{ft}^{\prime} \mathrm{s}$, and least-squares evaluation of level energies and $B$ feedings in a radioactive decay data set, to programs that check adopted $J \pi$ values against $L$ values in reactions and against gammaray multipole character. All analysis and checking programs operate directly on the data sets, and the output from, for example, the conversion coefficient and $\log \mathrm{ft}$ programs, can if ciesired be automatically fed back into the data sets. At all stages following data entry, the hand copying of numbers is kept to a minimum. 


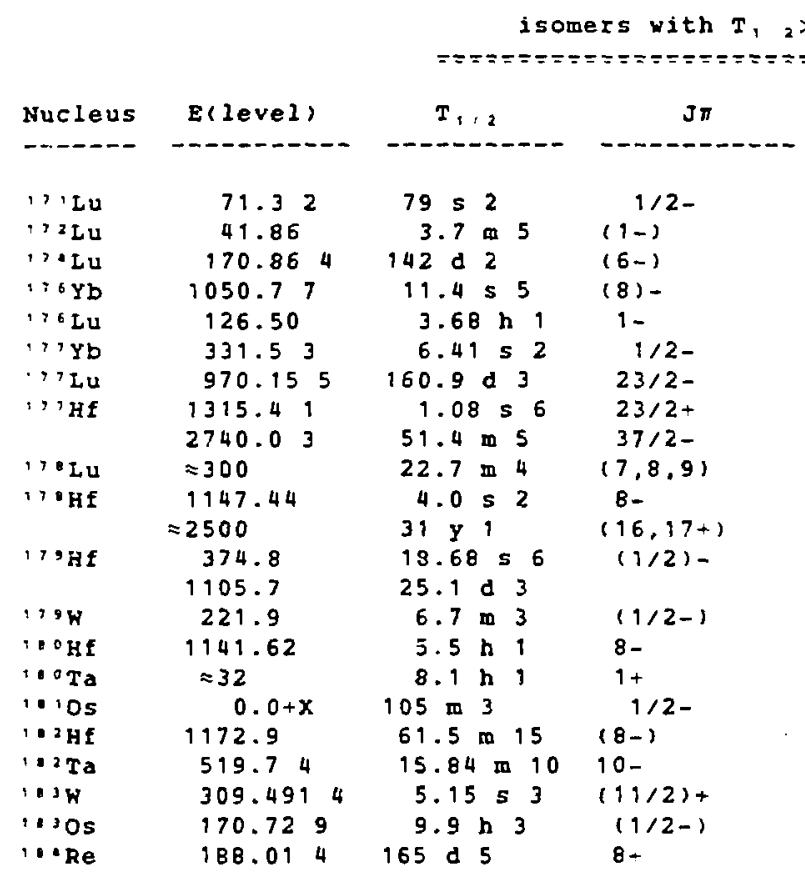

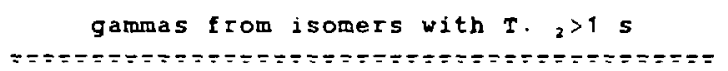

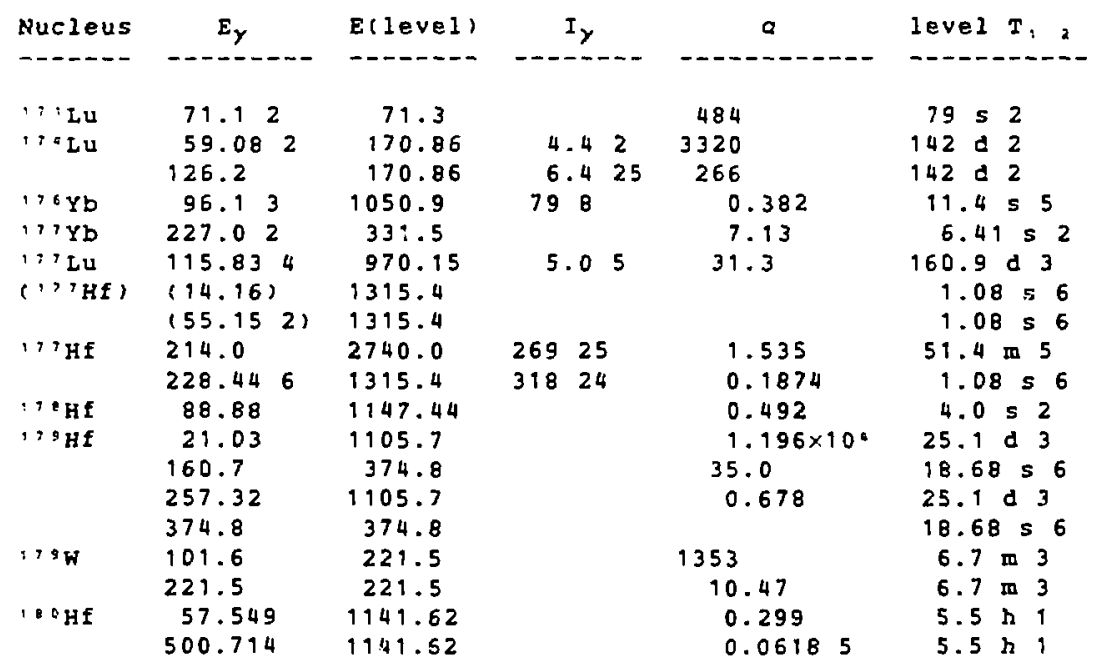

Fig. 1. Isomeric levels and gammas with $\mathrm{T}_{1 / 2}>1 \mathrm{~s}$. 
When the mass chain is finished and the evaluator has submitted it for publication, it is subjected to a thorough review. The final version of the mass chain then appears in the Nuclear Data Sheets and is entered into the ENSDF file. Once in the file, the data in that mass chain become part of an extensive bank of data that can be retrieved in a variety of forms.

\section{OUTPUT FROM ENSDF}

As of June 1985, ENSDF contained 1948 Adopted Levels data sets, 2396 decay data sets, and 4257 reaction data sets. Information in these data sets is retrievable by nucleus ( $A, Z$, and/or $N$ ), by class (odd-A, even-N = 200-214, etc.), by reaction or decay, o, by reference. The output can be of the form of level-scheme drawings, ] tables of nuclear properties, $l$ tables of atomic and nuclear radiations, ${ }^{3}$ or computer files of nuclear and radiation properties. See further references ${ }^{4}$ for other exanples of output from ENSDF.

of particular interest to attendees at this talk might be a listing of nuclear isomers within a given range of half-lives. Figure 1 is a subset of a listing of isomers with $T_{1 / 2}>1 \mathrm{~s}$ and the properties of the $\gamma^{\prime} s$ from these isomers.

This has been a brief overview of the Evaluated Nuclear Structure Data File, ENSDF, with a few examples of those types of information that can be extracted from that file. Those of you who may be interested in accessing the file or who would like more information on the system are invited to contact me or the National Nuclear Data Center at BNL.

\section{REFERENCES}

1. Nuclear Data Sheets, published by Academic Press, New York.

2. W. B. Ewbank and M. R. Schmorak, "Eraluated Nuclear Structure Data File - A Manual for Preparation of Data Sets," Oak Ridge National Laboratory Report ORNL-5054/R1 (February 1978).

3. M. J. Martin, "Nuclear-Decay Data for Selected Radionuciides," A Handbook of Radioactivity Measurements Procedures, Appendix A of NCRP Report No. 58, second edition (1985); M. J. Martin, "Radioisotopes," in Encyclopedia of Chemical Technology, Vol. 19 (John Wiley, New York, 1982), pp. 682-785.

4. W. B. Ewbank, "Versatile Output from a Simple Numeric Data File," in Proccedings of the Sixth International CODATA Conference, edited by B. Dreyfus (Pergamon Press, New York, 1979), pp. 359-369; W. B. Ekbank, "Systematics of Y'rast Levels in Nuclei," in Proceedings of the International Conference on Nuclear Physics, LBL-11118 (1980), p. 322; 11. B. Ewbank, "Status of Transactinium Nuclear Data in the Evaluated Nuclear Structure Data File," in Proceedings, IAEA Advisory Group Meeting on Transactinium Isotope Nuclear Data, IAEA-TECDOC-232 (1980), pp. 109-141; W. B. Ekbank, Y. A. Ellis, and M. R. Schmorak, Nucl. Data Sheets 26, 1 (1970). 


\section{DISCLAIMER}

This report was prepared as an account of work sponsored by an agency of the United States Government. Neither the United States Government nor any agency thereof, nor any of their employees, makes any warranty, express or implied, or assumes any legal liability or responsibility for the accuracy, completeness, or usefulness of any information, apparatus, product, or process disclosed, or represents that its use would not infringe privately owned rights. Reference herein to any specific commercial product, process, or service by trade name, trademark, manufacturer, or otherwise does not necessarily constitute or imply its endorsement, recommendation, or favoring by the United States Government or any agency thereof. The views and opinions of authors expressed herein do not necessarily state or reflect those of the United States Government or any agency thereof. 